\title{
REGIÃO FENOMENOLÓGICA \& ESFERA PSÍQUICA EM SARTRE: ESBOÇO PARA UMA GENEALOGIA DO MÁGICO
}

\author{
Gustavo Fujiwara $^{1}$ \\ Universidade Federal de São Paulo (UNIFESP) \\ (D) http://orcid.org/0000-0002-3971-9632
}

\begin{abstract}
RESUMO:
Este artigo visa analisar a categoria do mágico em duas obras fenomenológicas do filósofo francês Jean-Paul Sartre, quais sejam: $L a$ transcendance de l'Ego (1934) e Esquisse d'une théorie des émotions (1938). Em ambos os textos, o expediente do mágico é recorrente e assinala, por sua vez, uma certa experiência (de fuga) da consciência que poderíamos nomear como anti-fenomenológica. Ademais, este registro do mágico constitui para Sartre um modo, digamos, privilegiado no que tange à análise da ininteligibilidade da relação da consciência com o mundo, com os outros e consigo mesma.
\end{abstract}

PALAVRAS-CHAVE: Consciência; Psíquico; Mágico; Fenomenologia; Intencionalidade.

\section{PHENOMENOLOGICAL REGION \& PSYCHIC SPHERE IN SARTRE: SKETCH FOR A GENEALOGY OF MAGIC}

\begin{abstract}
:
This article aims to analyze the magic category in two phenomenological works from the French philosopher Jean-Paul Sartre, namely: $L a$ transcendance de l'Ego (1934) and Esquisse d'une théorie des émotions (1938). In both texts, the magic expedient is recurrent and points out a certain consciousness experience (of escape) that we could appoint as antiphenomenological. Furthermore, this magic record constitutes to Sartre a privileged way, shall we say, in respect to the intelligibility's analysis of the relation between consciousness and world, with others and itself.
\end{abstract}

\footnotetext{
${ }^{1}$ Mestre e doutorando em Filosofia Francesa Contemporânea pela Universidade Federal de São Paulo (UNIFESP), São Paulo - Brasil, sob a orientação do professor Doutor Alexandre de Oliveira Torres Carrasco. E-mail: fujiwaragustavo@gmail.com
} 
KEYWORDS: Consciousness; Psychic; Magic; Phenomenology; Intentionality.

\section{Campo transcendental e região psíquica em La transcendance de l'Ego}

De larga visada fenomenológica, o opúsculo La transcendance de l'Ego postula um duplo movimento: a partir da "limpeza" do campo da imanência via intencionalidade, Sartre recusará o Eu como um habitante da consciência, cujo resultado será a divisão entre uma região estritamente fenomenológica e outra psíquica, avessa às leis da primeira. Não obstante, no ato de fundamentação do psíquico como o objeto das teorias psicológicas, $T E$ poderá também ser lido como os "prolegômenos à toda psicologia futura" ${ }^{2}$. Grosso modo, a consciência, sob as lentes sartreanas, prescinde de um Eu unificador, pois, nos próprios vividos intencionais, ela opera sua síntese permanente: é o objeto quem lhe confere sua unidade e sua síntese. Sob o veio deste olhar, o Ego transcendental husserliano ${ }^{3}$ - esfera normativa que atua fora desse fluxo concreto dos vividos - não teria razão de ser tendo em vista esta radicalização da intencionalidade efetuada pelo filósofo francês, logo: "o cogito dispensa um Eu na exata medida em que ele procede através de uma visada intencional de si". (DE COOREBYTER, 2003, p. 46-47). Desta feita, o mecanismo intencional da consciência, tal como Sartre a compreende, exclui toda forma de "vida interior" e até mesmo o Eu de pretensões normativas. Aprofundando a tese central que orbita em torno de $T E$, o jovem normalien fará do Ego transcendental um Ego empírico (psíquico), apreendido na passagem da consciência irrefletida à consciência reflexiva ou consciência de segundo grau.

Ora, o campo transcendental assegura, graças ao princípio da intencionalidade, a síntese e a auto- unificação da consciência quando de sua apreensão do objeto ${ }^{4}$. Disso decorre que o objeto, (unidade transcendente real) por não ser representação, exclui a possibilidade de ser

\footnotetext{
2 "A consciência assim liberada, via intencionalidade, Sartre se impôs de imediato, ainda segundo Beauvoir, uma árdua tarefa: a revisão de toda a psicologia. Não é outra coisa o que ele procurará fazer no sei primeiro texto (...) Essai sur la Transcendance de l'Ego. "Revisar toda a psicologia": na verdade, esse curto ensaio não tem todo esse fôlego; ele é antes o começo dessa tarefa. Sartre procurará, nesse pequeno texto, apenas "esboçar uma teoria do objeto psíquico", isto é, fundamentar o psíquico, objeto da psicologia." (MOUTINHO, 1995, p. 8).

${ }^{3}$ Sobre a instauração do Ego transcendental, ver os $§ 57$ e $\$ 80$ de Ideias.

4 “Assim, o objeto, enquanto transcendente, torna desnecessário o recurso ao Eu unificante: na medida em que é verdadeiramente transcendente, ele já é aquela unidade real e , por isso mesmo, a unidade não forjada das consciências (...)" (MOUTINHO, 1993, p. 13). Ademais, este é também o sentido de uma fenomenologia do concreto, dado que é no mundo das coisas que a consciência opera sua síntese de unificação e individualização.
} 
unificado por um Eu. No campo da imanência, por seu turno, há um síntese das consciências, um fluxo contínuo que é capaz de por os objetos transcendentes fora dele. Inspirando-se nas Lições de Husserl, Sartre sublinhará que:

É a consciência que se unifica ela mesma e concretamente por um jogo de intencionalidades "transversais" que são as retenções concretas e reais das consciências passadas. Assim, a consciência remete-se perpetuamente a ela mesma, quem diz "uma consciência" diz toda a consciência e esta propriedade singular pertence a própria consciência, quaisquer que sejam suas relações com o Eu. (SARTRE, 2003, p. 97).

A consciência sartreana, a partir deste excerto, é de uma só vez "individual" e "impessoal", uma totalidade sintética; é o próprio fluxo desta consciência que constitui sua unidade e individualidade. Tanto do lado do transcendente, unidade real, como do lado do imanente, fluxo contínuo, o Eu transcendental aparece como desnecessário neste processo de unificação e individualização, sendo a consciência, ao contrário, aquela que torna possível a personalidade e a unidade deste Eu. Se "o Eu não tem razão de ser" é porque a antífona "toda consciência é consciência de...", além de operar um acesso imediato à objetividade, apresenta-se também como o expediente capaz de extirpar qualquer propriedade real e funcional do Eu na consciência ao afirmar sua característica absoluta: característica esta que compreende tanto a individualização quanto a auto-unificação. Deste modo, na própria imanência do ato intencional a consciência se transcende em direção aos objetos que lhe fornecem seu ponto de apoio, e em torno do qual sua unidade concreta se constitui; por outro lado, enquanto totalidade sintética e individual, ela unifica os vividos constitutivos da experiência. Em outros termos, no plano do objeto a consciência encontra uma unidade real, e no plano da imanência sua síntese.

Porém não basta afirmar a esterilidade do $\mathrm{Eu}$ no processo de unificação e individualização, deve-se assinalar que ele é prejudicial e ameaça a translucidez da consciência, "noutras palavras, buscar-se-á agora fixar os danos causados pelo Eu transcendental, e isso se fará apontando a deturpação no campo da consciência" (MOUTINHO, 1995, p. 15). Em resumo, o Ego causa danos ao campo transcendental devido à sua opacidade que acabaria dividindo a consciência, arrancando-a para fora de si mesma, além de impedir uma plena compreensão da intencionalidade. Ele é nocivo à imanência porque, por princípio, vimos que a consciência é clara como uma ventania, um vazio estrutural, uma recusa incessante em ser substância e receptáculo ${ }^{5}$. A partir da definição da consciência como totalidade sintética e absoluta, a fenomenologia extirpou do $\mathrm{Eu}$ suas qualidades formais de

5 Ver o artigo sartreano "Uma ideia fundamental da fenomenologia de Husserl: a intencionalidade". 
unificação e de individualização tanto do lado do transcendente como do lado do imanente, para na sessão $B$ do opúsculo ( $O$ Cogito como consciência reflexiva), mostrar que suas características de permanência, identidade e indivisibilidade não denotam uma instância originária e fundadora, mas, ao contrário, um ser transcendente, um existente real e derivado, uma unidade ideal e indireta das consciências refletidas, um Eu a favor do psíquico ${ }^{6}$. Ao arquitetar a consciência, em primeiro lugar, como consciência irrefletida, o filósofo faz observar que neste primeiro grau não há $\mathrm{Eu}$, mas apenas atividade intencional e impessoal.

Nesta toada, o Eu parece surgir na passagem da consciência de primeiro grau à consciência de segundo grau ou consciência refletida. $\mathrm{O}$ essencial da passagem de um estado a outro de consciência parece estar na aparição de um ego que afirma sua permanência para além da instantaneidade ${ }^{7}$ dos vividos. Por conseguinte, a reflexividade que faz com que ele apareça, altera a apoditicidade e a adequação das "Erlebnissen": "Husserl é o primeiro a reconhecer que um pensamento irrefletido sofre uma modificação radical ao se tornar refletido. (...) a reflexão modifica a consciência espontânea" (SARTRE, 2003, p. 100-101). Além disso, o Eu não é uma evidência nem adequada e nem apodítica ${ }^{8}$ por se apresentar como uma realidade opaca cujo conteúdo é preciso desenvolver. De uma consciência a outra, a tipologia apresenta-se da seguinte forma:

Nós podemos ver agora claramente quais são as diferentes modalidades estruturais da consciência: Sartre distingue três graus de consciência:

a) Uma consciência de primeiro grau, irrefletida, sem Eu, não posicional de si, autônoma. Ela é um absoluto: sua existência não implica àquela da consciência reflexiva. Quando leio, a consciência de primeiro grau é a consciência completa do ato de ler, a consciência absorvida.

\footnotetext{
6 "O Ego transcendental das Meditações alterna, para Sartre, em Ego empírico, o formal se torna psíquico (...). Sartre observa neste Ego, vazio e concreto, um avatar da figura clássica da alma ou da personalidade, um constituído que indevidamente carrega o papel de um constituinte." (DE COOREBYTER, 2003, p. 57).

${ }^{7}$ Mais para frente mostraremos que o critério de evidência de TE passa pelo instante da aparição do X.

${ }^{8}$ A apoditicidade e a adequação serão os dois elementos que irão distinguir os vividos e o Eu: "Além disso, no caso sartreano, as operações da consciência irrefletida ou do cogito pré-reflexivo passam pelas formas intuitivas adequadas do vivido (Erlebnis), elas serão, portanto, reguladas pelo instante e não pela temporalidade; daí sua apoditicidade, sua necessidade e sua indubitabilidade. Ora, o Ego (e, por extensão, a vida reflexiva), ao se caracterizar como intrinsecamente duvidoso, será regulado pelo modelo da percepção cada Abschattung dando-se inadequadamente prefigura uma profundidade inesgotável. O peculiar e o próprio dessa versão sartreana está no rigor da clivagem, que assevera a irracionalidade postulada do Ego porque sua incompletude performativa - intuição inadequada, apresentação por perfis - (...).” (CARRASCO, 2006, p. 127).
} 
b) Uma consciência de segundo grau, que reflete e supõe a primeira, faz aparecer o Eu, mas permanece não tética de si. Cogito egológico, a consciência de segundo grau é aquela que perturba ou interrompe a consciência mergulhada na leitura, e que liga o fato de ler a um eu (moi), ao sujeito da leitura.

c) Uma consciência de terceiro grau, que visa a si mesma como consciência reflexiva: toda consciência reflexionante permanece nela mesma irrefletida, (é preciso um novo ato de terceiro grau para colocá-la). O Cogito fenomenológico, é capaz de refletir a si mesmo sem postular um Eu, esta consciência esforça-se em apreender sem alterar a consciência irrefletida ou reflexiva da leitura. (MOUILLE, 2000, p. 44 45) ${ }^{9}$

Ao constatarmos, en passant, que a aparição de uma egologia só pode ser pensada a partir da passagem do irrefletido ao reflexivo, fazendo do Ego, por isso mesmo, uma espécie de resíduo da atividade constitutiva da consciência, mais precisamente o correlativo noemático da reflexividade, vejamos neste momento como este Ego se apresenta como polo das entidades psíquicas: estados ações e facultativamente das qualidades. Dirá Sartre:

O Ego não é diretamente unidade das consciências refletidas. Existe uma unidade imanente dessas consciências, é o fluxo da Consciência se constituindo ele mesmo como unidade de si mesmo - e uma unidade transcendente: os estados e as ações. O Ego é unidade de estados e ações - facultativamente qualidades. Ele é unidade de unidades transcendentes e transcendente ele mesmo. É um polo transcendente de unidade sintética ${ }^{10}$, como o polo-objeto da atitude irrefletida. (SARTRE, 2003, p. 108).

Neste esteio, estados, ações e qualidades são as categorias da percepção psíquica que estruturam o sistema de apreensão psicológica, a paisagem, a camada desta região psíquica ${ }^{11}$ no qual emerge o Ego para lhes servir de unidade sintética. Na medida em que avançarmos na descrição crítica desta região, ficará nítido que o psíquico é o reino das falsas adequações, do fetichismo, da mágica: lá o visado não coincide com o apreendido, aquilo que aparece não é aquilo que é ${ }^{12}$. Para demonstrar o

\footnotetext{
${ }^{9}$ Além desse esquema, o leitor pode consultar também a divisão feita por Leo Fretz em seu artigo "Individuality in Sartre's philosophy" (pp. 74-75) publicado no The Cambridge Companion to Sartre, 1999.

${ }^{10}$ Logo, um núcleo de constituição objetiva.

11 Por psíquico entendemos uma região anti-fenomenológica que rompe com a estrita adequação entre a consciência e o fenômeno.

12 De antemão faz-se intrínseco notar que é o próprio modo desinencial de aparição do psíquico que faz dele essa região "às avessas".
} 
caráter fetichista e mágico do psíquico, o famoso exemplo da passagem da repulsa ao ódio é aqui intrínseco. Vejamo-lo:

Vejo Pierre, sinto como que uma alteração profunda de repulsão e de cólera quando o avisto (eu já estou sobre o plano reflexivo): a alteração é consciência. Eu não posso me enganar quando digo: eu provo neste momento uma violenta repulsão por Pierre. Mas esta experiência de repulsão é ela o ódio? Evidentemente não. Ele não se dá, aliás, como tal. Com efeito, eu odeio Pierre durante muito tempo e eu penso que eu o odiarei sempre. Uma consciência instantânea de repulsão não saberia ser meu ódio. Se mesmo que eu a limitasse ao que ela é, a uma instantaneidade, eu não poderia mesmo mais falar de ódio. Eu diria: "Eu tenho repulsa por Pierre neste momento", de modo a não comprometer o futuro. Mas precisamente por esta recusa de comprometer o futuro eu cessaria de odiar. (SARTRE, 2003, p. $108-109$ )

A consciência instantânea de repulsa não poderia se apresentar como consciência de ódio na medida em que ela extravasaria a estrutura instantânea da própria consciência. Ainda que ambas as experiências se deem ao mesmo tempo, o ódio se entrega como não limitado à repulsa, ele ${ }^{13}$ ultrapassa o instante preciso no qual Pierre é apreendido; "a constituição do psíquico se mostrou como uma 'passagem ao infinito': o ódio é unidade transcendente de uma infinidade de consciências coléricas (...)" (MOUTINHO, 1995, p. 105) e para tanto, o critério de evidência da reflexão é radicalizado por Sartre ${ }^{14}$. Ele é eminentemente radicalizado, pois a consciência é apresentada como um ser que se determina à existência a cada instante sem que se possa conceber nada antes dela. Libertada dos domínios egológicos e psíquicos, a consciência pura forja "sua existência una a cada instante, sem nenhuma conexão entre os momentos isolados de suas vivências, sem nenhuma direção apontada por sua conjunção" (SACRINI, 2012, p. 118): cada instante de nossa vida nos revela uma criação sempre $e x$ nihilo.

Por conseguinte, devemos concluir que o ódio é um objeto transcendente que transborda o instante através do qual o mecanismo constitutivo da consciência se desenrola, ultrapassa os dados da consciência

\footnotetext{
${ }^{13}$ Ainda sobre a permanência do ódio: "Ele se dá, em e por cada movimento de desgosto, de repulsão e de cólera, mas ao mesmo tempo ele não é nenhum deles, ele escapa a cada um afirmando sua permanência. Ele afirma que já aparecia quando ontem eu pensei em Pierre com tanto furor e que ele aparecerá amanhã." Sartre (2003, p. 109).

14 Falamos em "radicalização do critério de evidência", pois Husserl, ao contrário do instantaneísmo sartreano, aceita diferentes graus de evidência na fenomenologia, "graus diretamente ligados à modulação temporal das vivências da consciência.” (SACRINI, 2012, p. 117). Para Sacrini, este é um dos tantos pontos que afastam Sartre de Husserl, ou ainda, sua reflexão pura da reflexão fenomenológica, ver: SACRINI, Marcus. "Sartre entre reflexão fenomenológica e reflexão pura”, in: Philósophos, 2012.
} 
refletida. Esse objeto transcendente aparece sempre como a crença das consciências coléricas tencionadas no passado e no futuro, ele é sempre permanência indevida, a unidade transcendente desta infinidade de consciências coléricas. Quando digo "eu odeio", "eu amo", estou operando uma verdadeira passagem ao infinito, estou me deslocando para fora do fluxo concreto das vivências da consciência, conferindo a esse objeto um modo desinencial que escapa da adequação entre o ser e o aparecer. Portanto, quando afirmo minha consciência de repulsa por Pierre, no exato momento em que eu o encontro, isso é certo, mas "é e permanecerá sempre duvidoso que eu o odeie" (SARTRE, 2003, p. 109). Devemos então afirmar que o ódio, ao ultrapassar a adequação do vivido de repulsa, é um objeto transcendente apreendido pela consciência de segundo grau. A distinção entre a repulsa e o ódio é fundamental para que Sartre prepare o terreno para dois tipos diferentes de reflexão: uma pura, adequada e outra impura (cúmplice), inadequada - "a distinção metodológica da reflexão pura e da reflexão impura está no coração da fenomenologia sartriana" (CABESTAN, 2004, p. 300) ${ }^{15}$. Estas duas reflexões aparecem como um instrumento operatório fenomenológico capaz de identificar ou não a origem transcendental de um vivido qualquer.

Esta reflexão impura, avessa à reflexão purificadora, opera uma passagem ad infinitum, constitui de forma brusca o ódio através da vivência de repulsa como seu objeto transcendente, ela afirma mais do que sabe, ultrapassa os dados de minha consciência, isto é, os vividos instantâneos. O estado, quando tomado por este tipo de reflexão impura “(...) estende a instantaneidade do cogito para envolver as três dimensões temporais" (COOREBYTER, 2000, p. 403). Nestes termos, a reflexão cúmplice do estado ódio "(...) reuni a sinopse do diverso imanente em uma unidade de sentido e de ser que se dá por independente das Erlebnisse reunidas, mesmo que ele somente se ateste através dessas Erlebnisse" (COOREBYTER, 2000, p. 403). Frisemos: o ódio não é um vivido de consciência tal como o é a repulsa, ele é um objeto real e transcendente apreendido por uma reflexão inadequada, ele não aparece sob o regime da adequação instantânea. Sob este aspecto, a reflexão impura ultrapassa a consciência de repulsa operando uma passagem ao infinito pela qual o estado de ódio é constituído, ela envolve as Erlebnisse com um sentido até então ausente da imanência: "ela transborda a instantaneidade da consciência e ela não se dobra a lei absoluta da consciência pela qual não há distinção possível entre a aparência e o ser" (SARTRE, 2003, p. 109). No entanto, isso não significa que o ódio seja uma simples hipótese vazia ou um conceito ilusório; ele é de fato um objeto transcendente de natureza duvidosa, constituído a partir da vivência concreta de repulsa, uma passividade.

15 CABESTAN, PHILIPPE. L'être et la Conscience. Recherches sur la psychologie et l'ontophénoménologie sartriennes. Paris: Éditions OUSIA, 2004. 
Todavia, ainda que este objeto se dê através da vivência, a relação entre o ódio e a consciência instantânea de desgosto é construída de maneira a misturar de uma só vez as exigências do ódio (ser primeiro, ser origem) e os dados certos da reflexão (espontânea), ou seja, a consciência de desgosto aparece como uma emanação do ódio subvertendo a verdadeira ordem de constituição fenomenológica que atesta, em primeiro lugar, a aparição desse vivido e depois, sua constituição cujo sentido é transcendente; o psíquico institucionaliza a inadequação entre ser e aparecer ${ }^{16}$. Em outros termos, é no próprio processo constitutivo de apreensão do vivido de repulsa que o ódio se constitui e, junto dele, a reflexão impura (condição de possibilidade do aparecimento do Eu psíquico). Finalmente, a partir do exemplo supracitado, torna-se evidente a divisão efetuada entre o campo transcendental impessoal e a região psíquica. Curiosamente, no processo de limpeza do campo transcendental, (a parte negativa de $T E$ ) havíamos destituído do Eu suas prerrogativas formais ao insistirmos sobre o fato de que a consciência realiza sua própria unificação e individualização, e que o objeto aparece como a unidade real; tanto do lado do imanente como do lado do transcendente o Ego se mostrava absolutamente desnecessário. Neste ponto, ao reconstituirmos sua transcendência, veremos que o papel destinado a ele será o da unificação e síntese das entidades psíquicas (estados, ações e qualidades): "o Ego está do lado do psíquico" (SARTRE, 2003, p. 114). Uma ressalva se impõe: este processo que torna o Eu formal desnecessário é válido apenas a partir da consciência irrefletida, do campo transcendental impessoal. Somente quando passamos ao plano reflexivo, sobretudo o da reflexão impura, constata-se que o Ego psíquico "é análogo ao objeto na atitude irrefletida: ambos aparecem como polos-objetos, como unidades sintéticas transcendentes, com a diferença de que o Ego, ao contrário daquele, é unidade forjada" (MOUTINHO, 1993, p. 26). Ainda que fosse tentador "constituir o Ego em 'polo-sujeito' como esse 'poloobjeto' que Husserl coloca no centro do núcleo noemático" (SARTRE, 2003, p. 114), o Eu será a unidade indireta das consciências refletidas; o estado, a ação e a qualidade, por seu turno, a unidade direta de uma atitude reflexiva. O Ego (por sua transcendência) não pode figurar como esse $\mathrm{X}$ suporte, noemático, ${ }^{17}$ na medida em que ele não permanece independente

\footnotetext{
${ }^{16}$ É importante notar que essa relação é construída de maneira a administrar as exigências psíquicas do ódio (ser primeiro e unificador). A emanação -elemento central para a compreensão da ligação entre os estados psíquicos e a reflexão espontânea- indica o fetichismo pelo qual a região psíquica altera a verdade ordem fenomenológica de aparição entre a repulsa e o ódio. Isso faz surgir a primeira antinomia do psíquico posto que a repulsa "dá-se de alguma maneira como se produzindo ela mesma na ocasião do ódio e graças ao ódio" (SARTRE, 2003, p. 111). O psíquico opera sempre a partir desse imbróglio constitutivo, ele existe sob a forma da inversão dos sentidos ao institucionalizar a inadequação entre o ser e o aparecer.

17 Ainda: "Ora, precisamente, um suporte não pode ser assim comprometido pelo que ele suporta se não no caso em que ele é uma totalidade concreta que suporta e contém suas
} 
das qualidades psíquicas, ou seja, na exata medida em que ele está sempre comprometido com os seus estados. Aparecendo sempre no horizonte da região psíquica, o Ego não pode ser separado dos estados, ações e qualidades; ele existe como a totalidade transcendente de unificação dessas entidades (também transcendentes); ele "é para os objetos psíquicos o que o mundo é para as coisas" (SARTRE, 2003, p. 115). No imbróglio da esfera psíquica, cada novo estado é remetido ao Ego como sua origem, pois a reflexão impura o apresenta como a fonte mesma das entidades psíquicas, ele se liga a elas através de uma produção poética; ele aparece como a fonte dos estados e os sustenta por meio de uma espontaneidade conservadora, encantada e mágica.

Entrementes, qual seria aqui o sentido do mágico? Este termo deve ser entendido aqui sempre à luz do exame crítico do campo transcendental. Ao forjarmos uma lei eidética para a consciência, orientamo-nos a partir deste fato originário que ordena e institui um campo lógico. A razão, galvanizada pela fenomenologia, acentua a primazia da consciência irrefletida sobre as demais consciências, ela refuta o Eu transcendental, o reino da subjetividade, afirma a relação fundamental entre momento constitutivo e momento empírico, enfim, ela dá a tônica do discurso que se pretende fenomenológico. O reino do psíquico, ao contrário, opera sempre às avessas, o Eu é solicitado como polo de unificação, há sempre o falso sentimento da subjetividade, ele rompe com a translucidez da imanência do campo transcendental. Se isso está correto, esta noção de mágica serve para indicar a ruptura que se efetua entre o aparecer e o ser, ela sinaliza um esfera anti-fenomenológica que, no entanto, possui existência. A mágica de que fala Sartre mantêm estritos elos com tudo aquilo que não é racional e adequado, ela é o avesso da racionalidade em fenomenologia, ela é o campo da atitude natural, o arauto do homo psicologicus. Assim, o psíquico é sempre produtor de feitiçaria e magia, daí o sentido de seu vocabulário místico: emanação, criação, participação, etc... Tão logo este fato tenha sido por nós assinalado, vemos que tudo se passa como se cada novo estado, ação ou qualidade fosse, antes de ser apreendido pela consciência, religado ao Eu como sua origem. Todavia, em primeiro lugar, o que realmente é primeiro são as consciências, através das quais se constitui os estados, depois, através deles, o Ego. Sob o registro da reflexão impura, a constituição é feita em sentido inverso, o que significa que "as consciências são dadas como emanando dos estados e os estados como produzidos pelo Ego" (SARTRE, 2003, p. 118); encontramo-nos diante do fetichismo com o qual a região psíquica se apresenta, ou seja, a inversão da constituição como característica fundante da esfera psíquica. No que diz respeito à "espontaneidade egológica", segue-se que a "consciência projeta sua própria

próprias qualidades. O Ego não é nada fora da totalidade concreta dos estados e ações que ele suporta." (SARTRE, 2003, p. 115). 
espontaneidade no objeto Ego para lhe conferir o poder criador que lhe é absolutamente necessário" (SARTRE, 2003, p. 118).

Ao explorar a geografia enganosa dessa região psíquica, caminhamos sempre em presença do $\mathrm{Eu}$, ele aparece como íntimo à consciência, ele se entrega à reflexão como uma interioridade fechada sobre si mesma: por conseguinte, se me afasto ele também se afasta, se me aproximo ele executa o mesmo movimento de aproximação. A lei de existência do psíquico é a de negar a lei eidética do campo transcendental pré-pessoal, é a de efetivar falsas interioridades ligadas às falsas presenças. Em uma palavra, as entidades psíquicas se nutrem da falta de adequação que é inerente a sua razão de ser. Diante desse fato concluímos que: se a marca eidética do vívido é a de aparecer como identidade absoluta com o ser, no psíquico, por sua vez, tal identidade é sempre faltante. Ainda que a natureza duvidosa do psíquico faça do Eu o produtor de suas entidades (estados, ações e qualidade), isso não é de todo suficiente para que possamos explanar seu aparecimento para a consciência de segundo grau. Daí a ligeira desconfiança de Sartre ao afirmar que "talvez, com efeito, a função essencial do Ego não é tanto teórica quanto prática" (SARTRE, 2003, p. 128), sendo o seu papel primeiro o de encobrir a consciência de sua própria espontaneidade. Tudo se passa como se a consciência constituísse o Ego como uma falsa representação de si mesma, dado seu temor diante da descoberta da liberdade eidéticamente constituída. Sem querer dar exclusivamente ao problema acima as tonalidades forjadas pelo Ser $e$ o Nada (1945), ou seja, sem atribui-lo de uma ontologia da angústia existencial (a "luta" do para-si com o em-si), propomos o exame deste enleio a partir da liberdade radical estabelecida pela lei eidética da consciência transcendental. Ocorre que, experienciando sua própria estrutura intencional, a consciência, em um movimento contra si mesma, fornece ao Ego a espontaneidade (sempre mágica e degradada) que arremata nela a omissão; isso suscita quase que imediatamente uma diminuição de sua liberdade. Porém, esses ruídos que ameaçam o projeto sartreano são abafados caso não ignoremos a "dialética da liberdade", pois há

(...) liberdade contra si. E o "si" é a natureza no que concerne à liberdade que o quer mudar. Mas para que ele possa ser "si" é preciso antes que seja liberdade. Caso contrário, a natureza não é mais que exterioridade, portanto negação radical da pessoa. Mesmo o desamparo, isto é, a imitação interna da exterioridade, mesmo a alienação supõem a liberdade. (SARTRE, 2005, p. 300)

Em suma, poder-se-ia dizer que a consciência apreende o Eu como origem porque ela é inteiramente livre para tal e, partindo deste fato, a categoria do mágico (representada pelo psíquico) é reveladora de uma liberdade colossal e monstruosa. 


\section{0 mágico em Esquisse d'une théorie des émotions}

Publicado nos anos de 1938, o Esquisse d'une théorie des émotions é o único testemunho maior da obra inacabada La Psyché, figurando como sua introdução. Nesta obra, Sartre pretenderá promover uma concepção eidética e existencial do fenômeno emoção. Para tal, ele deve examinar as teorias psicológicas clássicas passando-as pela polaridade conceitual Husserl\Heidegger até chegar ao esboço de uma psicologia tornada eidética, logo, é questão observar se a psicologia da qual fala Sartre pode aproveitar o método e os ensinamentos que dispõe a fenomenologia. A consciência agramatical forjada por $T E$ deverá, doravante, contar com uma nova variação eidética e o conceito de psíquico tramar-se-á a partir do conceito fundamental de essência (eidos). Por conseguinte, aquela região nãofenomenológica representada pelo psíquico no ensaio sobre o ego transcendente, passará agora ao plano da essência da consciência dada a entrada do conceito de realidade-humana (tradução francesa do Dasein heideggeriano).

$\mathrm{Na}$ introdução de seu texto, Sartre pretende operar uma crítica metodológica à psicologia de sua época, por conseguinte, uma crítica que se atém exclusivamente à objetivação do fato psíquico e ao estatuto da descrição realizado pelos psicólogos. Segundo o filósofo, o psicólogo, antes de tudo, parte exclusivamente de fatos que não se organizam por si mesmos em uma totalidade sintética que "forneceria por si mesma sua significação" (SARTRE, 1995, p. 8), ou seja, ele parte de um dado empírico já constituído e que se repete com certa frequência: o psicólogo toma a noção empírica de homem sem tê-la definido e limitado a priori ${ }^{18}$. Em suma, ele ignora se o conceito de homem não é arbitrário, logo: "A psicologia espera utilizar o conceito de homem somente como um conceito a posteriori, construído pelo termo da operação experimental" (TOMÈS, 2010, p. 19) ${ }^{19}$. Entrementes, no caso particular da emoção, por falta de um conceito rigoroso de homem que teria permitido elucidá-la a partir da totalidade humana, o empirismo conduz o psicólogo a apreender a emoção como um fenômeno psíquico sem ligação essencial com outros fenômenos ${ }^{20}$. A consequência direta do descuido

\footnotetext{
18 A psicologia para Sartre “(...) não espera definir e limitar a priori objeto de sua investigação. A noção de homem que ela aceita é inteiramente empírica: há no mundo um certo número de criaturas que oferecem à experiência caracteres análogos." (SARTRE, 1995, p. 9).

19 "Préface à L'Esquisse d'une théorie des émotions de Jean-Paul Sartre", in: Esquisse d'une théorie des émotions. Paris: Hermann, 2010.

${ }^{20}$ Já pressentimos claramente a distinção entre a elaboração psicológica da emoção que não coloca em relevo a realidade-humana da elaboração operada pela psico-fenomenologia. Sendo assim, “(...) uma vez a emoção isolada do resto da realidade-humana, o psicólogo a explica, então, de acordo com a sua démarche analítica, privilegiando certos aspectos do fenômeno que ele novamente isolou: as reações corporais de um lado, as condutas e os
} 
conceitual é a de que há, para a psicologia, uma multiplicidade de fatos justapostos e não ordenados. Enfim, o métier psicológico diz respeito a essa característica indutiva ${ }^{21}$ que nos fornece apenas somas heteróclitas de fatos dispersos, o psicólogo aparece aqui como um mero colecionador de fatos isolados que privilegia o acidente ao essencial, o contingente ao necessário, nessa senda:

Esperar o fato é, por definição, esperar o isolado, é preferir, por positivismo, o acidente ao essencial, o contingente ao necessário, a desordem à ordem; é transferir ao futuro, por princípio, o essencial: "é para mais tarde, quando tivermos reunido um grande número de fatos". (SARTRE, 1995, p. 12)

A fatura desta crítica é incisiva: a ciência chamada psicologia não visa conhecer a totalidade sintética mundo e homem, antes, visa tão somente às possibilidades de certos fenômenos gerais. Ciência empírica e indutiva, a psicologia na época de Sartre apenas objetiva o psíquico, torna-o mero fruto do acaso, coleção vã de fatos distintos que, somados, jamais chegam a nenhum resultado concreto. No estudo particular das emoções, a descrição empírica da psicologia nada assevera sobre esta, antes, apresenta-a como uma simples desordem sem lei, como um mero acidente de percurso. Sem indagar sobre as condições de possibilidade de uma emoção, o psicólogo abjura uma compreensão mais vasta da realidade-humana como possível efetuadora das emoções. Ademais, esta compreensão parece até mesmo risível no nível desta ciência impregnada de positividade e empiria. Lê-se:

Quanto a estudar as condições de possibilidade de uma emoção, isto é perguntar se a estrutura mesma da realidadehumana torna as emoções possíveis e como as torna possíveis, isso pareceria ao psicólogo uma inutilidade e uma absurdidade: de que serve investigar se a emoção é possível, já que precisamente ela é? É à experiência igualmente que o psicólogo se dirigirá para estabelecer os limites dos fenômenos emotivos e sua definição. (SARTRE, 1995, p. 14 - 15).

Em todo caso, a investigação psicológica não busca as leis da emoção em totalidades sintéticas e essenciais da realidade humana, "mas ao contrário nos processos da própria emoção" (SARTRE, 1995, p. 16) concebida apenas como fato entre tantos outros fatos que nada significam. Manifestando um desejo profundo de positividade, a letra do discurso

estados de consciência propriamente ditos de outro. Também a emoção é para o psicólogo, ao mesmo título de não importa qual fenômeno natural tal como a atração, um fato desprovido de significação." (CABESTAN, 2004, p. 39).

21 “Os psicólogos não se dão conta, com efeito, de que é tão impossível atingir a essência amontoando os acidentes quanto chegar à unidade acrescentando algarismos à direita de 0,99.” (SARTRE, 1995, p. 12). 
psicológico está centrada na experiência sensível ou na experiência reflexiva que pressupõe uma certa representação normativa ou uma certa tese sobre o que deva ser a experiência. Disso, Sartre afirma que o empirismo da psicologia permanece insuficiente para a reconstituição da essência do homem e, por conseguinte, para a explanação em filigrana da emoção.

Nessa esteira, contra as insuficiências de tal ciência, Sartre convoca a fenomenologia de Husserl com a qual podemos distinguir a incomensurabilidade existente entre as essências e os fatos ${ }^{22}$. Em fenomenologia, cuja base de seu método é aquela da intuição eidética, se falamos de experiência, ao menos, referimo-nos à experiência das essências e dos valores; doravante, a noção conceitual de eidos opera uma verdadeira diferença teórica entre esta e a psicologia. É preciso considerar que "apenas as essências permitem classificar e inspecionar os fatos" (SARTRE, 1995, p. 17). Sobremaneira, ao principiar suas investigações a partir dos fatos psíquicos isolados de sua essência, o psicólogo não vislumbraria jamais o homem no mundo, ou seja, não alcançaria as emoções enquanto reações humanas contra o mundo (e assim providas de significação). Até este ponto, a démarche da crítica de Sartre à psicologia ateve-se exclusivamente a noção capital de essência. Se em $T E$ a censura à psicologia havia sido operada graças ao desconhecimento que ela possui da consciência espontânea irrefletida, aqui, trata-se de elucidar a origem do homem em situação, do psíquico e do mundo. É intrínseco que partamos das análises da essência da consciência constitutiva, pois o objetivo do estudo da emoção é mostra-la enquanto significação das essências das totalidades sintéticas ${ }^{23}$ : todo fato humano é, por essência, significativo. Doravante, a psicologia fenomenológica buscará compreender as emoções a partir das relações da consciência com o mundo e, para tal, ela deverá operar uma investigação eidética acerca dessas totalidades sintéticas. Explanar as totalidades sintéticas significa, por seu turno, dirigir-se às coisas mesmas, apreendê-las em carne e osso, enquanto eidos. Significa, finalmente, trabalhar com os ganhos teóricos da filosofia husserliana conquistados através da ideia de intencionalidade.

Se, em $T E$, o psíquico era um objeto transcendente que não se dava no fluxo concreto dos vividos, agora, ele passará a integrar a consciência, será um fenômeno da consciência diante do mundo, uma nova variação eidética desta, explanando a realidade-humana que se assume a si mesma. A

\footnotetext{
${ }^{22}$ Dirá Sartre (1995, p. 17) acerca da diferença entre fato e essência: "Se procuro os fatos psíquicos que estão na base da atitude aritmética do homem que conta e calcula, jamais chegarei a reconstituir as essências aritméticas de unidade, número e de operações.”.

23 "Aplicado a um exemplo particular, o estudo das emoções, por exemplo, o que vão produzir os princípios e os métodos do psicólogo? De início, nosso conhecimento da emoção acrescentar-se-á de fora aos outros conhecimentos sobre o ser psíquico. A emoção se apresentará como uma novidade irredutível em relação aos fenômenos de atenção, de memória, de percepção, etc.” (SARTRE, 1995, p. 14).
} 
equação "a realidade é precisamente a aparência" passa a valer para o psíquico, "é enquanto fenômeno que podemos alcançar a essência do psíquico e por aí fornecer bases sólidas para 'as generalizações do psicólogo (...)" (MOUTINHO, 1995, p. 101). Reenquadrar o psíquico como fenômeno significa, além disso, considerá-lo significante, assumido pela realidadehumana ${ }^{24}$. A significação, por sua vez, deve ser compreendida como aquilo que indica outra coisa, significar é indicar esta outra coisa de tal modo que "desenvolvendo a significação encontrar-se-á precisamente o significado" (SARTRE, 1995, p. 25). Nas tramas de Esquisse, deveremos considerar a emoção como significante, daí a tarefa da psicologia fenomenológica, qual seja: explicitar e elucidar a significação das condutas da consciência emocionada. De qualquer maneira, a emoção deve ser considerada sob o prisma fenomenológico-existencial, ela porta uma essência, tem estruturas organizadas e particulares: "a emoção é uma forma organizada da existência humana" (SARTRE, 1995, p. 26). Finalmente, podemos assinalar com mais rigor a fatura da polaridade Husserl-Heidegger: devemos falar da emoção tendo em vista tanto as leis eidéticas da consciência como a realidadehumana que assume seu próprio ser através de um modo existencial de compreensão. Nesse sentido, a psicologia fenomenológica, a partir do expediente conjugado da realidade-humana e da consciência, fornece-nos as estruturas eidéticas da consciência na qual a emoção, por seu turno, representa o todo da realidade-humana que se assume ela mesma emocionada; a afetividade humana só é possível na medida em que há uma predisposição existencial do homem em ser afetado.

Dito isso, ver-se-á que a teoria fenomenológica das emoções em Sartre é toda ela arquitetada para conceber a emoção como fato significativo que não comporta em seu mecanismo nenhuma sombra do inconsciente tal como concebido pela psicanálise freudiana. Ora, para que Sartre possa se desvencilhar das fantasmagorias do inconsciente freudiano (o justo oposto da definição de uma consciência absoluta), ele deverá afirmar que a emoção é, na verdade, uma consciência irrefletida que produz uma modificação mágica na estrutura global do mundo. Deste modo, se em TE o Ego possuía uma função prática de obscurecimento da liberdade da consciência, aqui a finalidade da emoção será a de mudar o objeto através da mudança do mundo. O filósofo novamente:

Neste momento podemos conceber o que é uma emoção. É uma transformação do mundo. Quando os caminhos traçados se tornam excessivamente difíceis ou quando não vemos caminhos, nós não podemos mais permanecer nesse mundo tão urgente e tão difícil. Todas as vias estão barradas, no entanto é necessário agir. Então tentamos mudar o mundo, isto é, vivê-lo

\footnotetext{
24 “(...) para a fenomenologia, todo fato humano é por essência significativo. Se você lhe remove a significação, você lhe remove sua natureza de fato humano. A tarefa de um fenomenólogo será, então, estudar a significação da emoção.” (SARTRE, 1995, p. 24).
} 
como se as ligações das coisas com suas potencialidades não fossem regradas por processos deterministas, mas pela magia. (SARTRE, 1993, p. 79)

Quando nos percebemos acuados diante dos processos deterministas do mundo, laçamo-nos com todas as forças nesta nova atitude que visa modificar a relação das potencialidades dos objetos com os meios determinados. Frisamos, ainda, que esta modificação não é consciente enquanto tal, ela é "a apreensão de ligações novas e de exigências novas" (SARTRE, 1993, p. 79). A impossibilidade ou o engendramento de uma tensão insuportável, faz com que a consciência apreende o objeto de uma nova maneira, ela se transforma para poder transformar as potencialidades do objeto em questão. Assim, o advir da consciência emotiva só se faz via apreensão de um mundo cujas estruturas deterministas se mostram insuportáveis. Diante de tais dados, os mecanismos da emoção são desvelados: ela é um fenômeno de consciência que visa mudar uma intenção ou uma conduta, e ela se entrega no plano irrefletido da consciência. Para que este ponto fique claro, tomemos como exemplo uma dada reação diante de um perigo eminente ${ }^{25}$. Suponhamos que um indivíduo caminha tranquilamente na rua quando, de repente, ele perceber vir em sua direção um cão feroz: suas pernas fraquejam, seu coração bate mais devagar, empalidece e finalmente desmaia. À primeira vista, nada parece menos adaptado do que esta conduta que abandona o sujeito aos perigos do animal. Todavia, tal realização, representa uma conduta de evasão, um refúgio pelo fato de não poder evitar este perigo através das vias normais e pelos encadeamentos deterministas do mundo; "a urgência do perigo serviu de motivo para uma intenção aniquiladora que comandou uma conduta mágica". (SARTRE, 1995, p. 83).

A tessitura fundamental da emoção está, portanto, ancorada nesta finalidade que provoca uma transformação mágica do mundo. Como dissemos, no caso do medo passivo, não podendo agir por vias normais, a emoção aniquila o animal feroz que avança em minha direção através do desmaio, ela o suprime como objeto de consciência, suprimindo a si própria: "são estes - aliás- os limites de minha ação mágica sobre o mundo" (SARTRE, 1995, p. 84). Doravante, na passagem da vigília ao desmaio, não nos deparamos com uma desordem puramente fisiológica tal como pretendiam alguns psicólogos clássicos; antes, o desmaio possui essencialmente uma finalidade de supressão, de aniquilamento de todo e qualquer perigo. Deste exemplo, podemos determinar que o mundo está calcado, magicamente, sob as intenções da consciência, "ele muda de qualidades, e de mundo difícil ele se torna um outro mundo, conforme as

\footnotetext{
${ }^{25}$ Devemos observar que na presente obra, Sartre analisa apenas quatro tipos de condutas emotivas (embora muitas outras existam); quais são elas: medo passivo, medo ativo, tristeza passiva, tristeza ativa e alegria.
} 
novas intenções da consciência" (TOMÈS, 2010, p. 83). Ao vir à baila, a consciência emotiva opera uma conduta finalista mágica, pois seu objetivo é o de suprir modificando totalmente o mundo e seus processos determinados.

Debruçando-se na análise eidética da tristeza (ativa e passiva), o filósofo empregará os mesmos termos da conduta mágica que assola a consciência diante dos meios deterministas do mundo. Na tristeza passiva, observamos o isolamento e a apatia com a qual o sujeito se apresenta diante de seus afazeres e diante de outras pessoas. Tal tristeza parece se caracterizar por uma conduta de impossibilidade ação. Antes de almejar a solidão, a conduta revela a mudança estrutural total do mundo operada por uma consciência. Não obstante, tendo perdido uma das condições ordinárias de sua ação no mundo, o indivíduo continua sendo constrangido a agir nele, mas sem esta dada condição ${ }^{26}$. Assim, a tristeza passiva é uma tentativa da consciência em "transformar a estrutura do mundo substituindo sua constituição presente por uma estrutura totalmente indiferenciada. Trata-se de fazer do mundo uma realidade afetivamente neutra (...)" (SARTRE, 1995 , p. 86). A tristeza passiva é também uma fuga diante dos caminhos sulcados pelas vias deterministas e objetivas do mundo, uma mudança estrutural deles. Acuada e acolhida em um canto sombrio, a consciência almeja, com todas as forças, escapar das dificuldades desse mundo, ela o torna monótono e indiferenciado. Deste fato, emanam todas as posturas corpóreas daquele que sofre uma profunda tristeza: o recolhimento e isolamento na penumbra, a solidão de um quarto à multidão, o silêncio ao invés do barulho, etc., são os correlativos noemáticos desta atitude; são inações que não passam de meios encontrados pela consciência para justificar um mundo tornado, magicamente, morno.

Passando às considerações acerca da tristeza ativa, indicamos que ela se manifesta através da exteriorização do sentimento. O exemplo perfeito desse tipo de tristeza é representado pela conduta da paciente psicasténica de Janet que deseja confessar-lhe algo extremamente difícil. Nos preâmbulos da confissão, ela chora e soluça, utiliza seu corpo para levar o psicólogo a uma atitude de atenção afetuosa. Através desses gestos, ela põe fora de alcance à ação a ser realizada, e "enquanto estiver possuída pelas lágrimas e os soluções, toda possibilidade de falar the é tirada" (SARTRE, 1995, p. 88). Ela chora e soluça precisamente para nada dizer, deixa a potencialidade do ato em suspenso para conseguir se livrar da

\footnotetext{
26 “(...) uma das condições necessárias ordinárias de nossa ação tendo desaparecido, o mundo exige de nós que nós ajamos nele e sobre ele sem ela. A maior parte das potencialidades que o povoam (trabalhos $a$ fazer, pessoas $a$ ver, atos da vida cotidiana $a$ cumprir) permanecem as mesmas. (...) Por exemplo, se fiquei sabendo de minha ruína, eu não disponho mais dos mesmos meios (carro particular, etc.) para realizá-las. É preciso que eu substitua aqueles meios por novos (tomar o ônibus, etc.); e é isso precisamente que eu não quero. A tristeza visa suprimir a obrigação de procurar essas novas vias (...)." (SARTRE, 1995, p. 86).
} 
liberdade que possuía em relação ao ato confessional. Há certa exageração mágica de dificuldade que fazem do mundo, ele aparece como "injusto e hostil, porque ele exige muito de nós, mais do é que humanamente possível lhe dar" (SARTRE, 1995, p. 89). Daí a assertiva de que a tristeza da paciente, sob a ótica sartreana, é uma comédia mágica de impotência e um abandono de responsabilidade. A teórica que possibilita uma tal afirmação acerca da tristeza, não é se não a própria liberdade infra-humana da consciência.

Tudo indica que na tristeza (mas também nos outros casos emotivos) a liberdade eidética da consciência entra em conflito com as estruturas organizadas e deterministas do mundo. Caso não houvesse uma dada liberdade que atravessasse a consciência por inteira, a análise de Sartre não poderia referir-se à conduta emotiva como uma conduta mágica, ou seja, como uma conduta imantada pela própria consciência. O sentido do mágico revela, então, que é a própria consciência que altera a si mesma para alterar, na sequência, o mundo que a cerca. Deste fato, é preciso considerar que a mudança do mundo, operada pela consciência mediante situações urgentes, é uma mudança impulsionada, galvanizada por esta liberdade absoluta que a acompanha em cada movimento. A crise de soluções da paciente é o indicador da angústia que provamos diante das possibilidades da consciência; não existe absolutamente nada, a não ser a própria consciência, que possa fundamentar nossas escolhas e ações no mundo. Portanto, sem o expediente dessa liberdade definida como parte estrutural dos mecanismos da consciência, Sartre, como já aludimos, não poderia sequer falar em conduta ou transformação mágica na emoção. Disso, devese admitir que o sentido mágico que recobre o mundo tem suas origens na própria consciência cujo mecanismo fenomenológica é aquele da intencionalidade.

\section{Do campo transcendental impessoal à abertura do mundo}

Após termos reunido os dois modos de ser da consciência percepção e emoção -, estamos aptos a mesurar o sentido da fuga propiciada por cada uma dessas consciências, seja em relação à sua auto-apreensão como liberdade eidética no opúsculo sobre o Ego transcendente, seja, como já denotamos em Esquisse, a partir de sua abertura ao mundo. Ego e emoção parecem operar, a partir de suas próprias estruturas, um itinerário acerca da magia. Em seu ensaio dos anos de 1934, lembremos, Sartre identificava as primeiras características do mágico a partir da distinção entre consciência e psiquismo. Assim, observando a aparição desse expediente teórico nos quadros de uma psicologia fenomenológica, cabe perguntar "como a magia se torna um conceito operatório para analisar as dimensões as mais salientes 
da consciência?" (MASSELOT, DASSONNEVILLE, 2012, p. 202) ${ }^{27}$. Nas investigações sobre o campo transcendental, notamos o recurso ao mágico quando o filósofo se depara, depois de ter mostrado à exaustão a inutilidade do Ego na unificação das consciências, sua participação em uma região psíquica que inverte a relação entre a consciência irrefletida e seus estados refletidos. Sob a insígnia de uma reflexão impura, Sartre identifica o que de Coorebyter (2000, pp. 475-479) nomeia como "as categorias dinâmicas: atualização, emanação e criação", cuja base se encontra na inversão da ordem fenomenológica: "o psíquico tem como signo distintivo compor um erro regrado, a degradação da imanência em quase-objeto tratado sobre o registro da transcendência" (DE COOREBYTER, 2000, p. 479). Perpassado por uma transcendência problemática ${ }^{28}$, o Ego possui uma pseudoespontaneidade, uma espontaneidade passiva e ininteligível, indicando o sentido mágico da psique. Constituindo o Ego como uma falsa representação de si mesma, a consciência "finge" escapar de sua liberdade eidética, ela se sedimenta nele a fim de escapar de sua miríade de possibilidades fundadas a partir de sua própria atividade intencional. $\mathrm{O}$ mágico, em regime de $T E$, está fundamentando nessa auto-negação da consciência em ser consciência constituinte impessoal.

Já em Esquisse, a dinâmica do mágico aparece ligado a um sentido existencial. A consciência emocionada, consciência irrefletida do mundo, experimenta e vivência um mundo cujas estruturas são difíceis; não podemos, simplesmente recorrendo à vontade, alterar de fato o complexo de utensilidade que rege as tramas do mundo:

A emoção aparece em um mundo que é vívido como difícil, ou seja, em um mundo no qual as potencialidades que o constituem e pelas quais se articulam a ação não são mais percebidas como realizáveis. (MASSELOT; DASSONNEVILLE, 2012, p. 207)

Através de seu estado emocionado, a consciência "modifica" o mundo de modo que ele não seja mais regrado por processos deterministas, mas sim pela magia: a consciência emotiva o transforma de acordo com suas intenções; entretanto, essa mudança não sinaliza nenhuma alteração real da ordem causal. Lembremos, por exemplo, o medo passivo no qual a consciência, diante de uma situação perigosa qualquer, suprime o perigo ao suprimir a si mesma a partir do desmaio. Investigando a consciência a partir do registro psico-fenomenológico, Sartre, ao contrário de $T E$, recorre ao

${ }^{27}$ MASSELOT, Nathanael; DASSONNEVILLE, Gautier. "Magie et constituition chez le premier Sartre. Vers une figure de la néantisation", in: L'année Mosaique: Objets qui nous hantent, objets qui nous tantent, numéro dirigé par Loic Nicolas et Aline Wiame. Lille, Belgique: EME editions, 2012, pp. 201-218.

${ }^{28}$ Ela é problemática pois, como vimos, ela extrapola sua função de unificação sintética transcendente das entidades psíquicas também transcendentes (estados, ações e qualidades). 
mágico para explicitar a relação - a abertura - da consciência ao mundo. Nesta toada, se a consciência emotiva é uma consciência irrefletida, deve-se conceber o mágico não mais a partir de uma operação reflexiva como ocorria quando da constituição do Ego (transcendência psíquica), mas como pertencente à própria estrutura da consciência de primeiro grau. Ao operar uma conduta mágica de evasão ${ }^{29}$, a consciência de Esquisse, além de se auto-apreender como pura liberdade absoluta, revela também suas experiências em mundo (situações) que lhe aparece carregado de dificuldades: "ela prova, ao mesmo tempo e repentinamente, sua absolutidade e sua finitude (...) assim como sua encarnação e sua situação" (MASSELOT; DASSONNEVILLE, 2012, p. 208). Transformando o mundo e a si mesma, localizamos nessa obra o sentido dinâmico do mágico, qual seja: "uma síntese irracional de espontaneidade e de passividade" (SARTRE, 1995, p. 108), ele institui uma consciência apassivada ${ }^{30}$. A tese dessa obra é a de considerar as emoções como uma maneira específica que a consciência têm de compreender seu ser-no-mundo como ser-no-mundo mágico:

\begin{abstract}
A emoção enquanto queda brusca da consciência no mágico é, portanto, um dos modos possíveis de ser-no-mundo (...). O modo mágico é inteiramente coerente. Nele, a consciência combate os perigos ou modifica os objetos sem a mediação dos utensílios, logo, sem distância. (...) A emoção constitui assim um retorno da consciência à atitude mágica, uma das grandes atitudes que lhe são essenciais. Trata-se de uma possibilidade existencial originária, que está sempre à disposição da consciência. (BRUZAN, 2007, pp. 204-205)
\end{abstract}

Inicialmente, a categoria do mágico é requerida por Sartre no que diz respeito à constituição do Ego e à inversão por ele operada no fluxo dos vívidos, o léxico do mágico (emanação, processão, participação, feitiçaria, etc.) é exclusivo de uma região psíquica contrária ao campo transcendental. A partir do psíquico, a consciência se deixa ofuscar pela egologia, ela se coloca como alteridade quando de sua auto-apreensão como vazia e livre. Todavia, após a fenomenalização do psíquico realizada em Esquisse, o mágico advém como pertencendo à própria estrutura da consciência, ele adquire, como vimos, um sentido existencial que versa nas possibilidades de recusa ou de nadificação do mundo (desrealização do mundo). O mundo, até então ausente das descrições puramente fenomenológicas de $T E$, emerge na tematização da psicologia fenomenológica como uma das condições à magia: na origem da emoção observa-se uma degradação espontânea e vívida da consciência face ao mundo. Entrementes, dos anos de 1934 até os

\footnotetext{
29 “Assim, através dessas condutas, nós intencionamos magicamente certas qualidades sobre os objetos verdadeiros. Mas essas qualidades são falsas.” (SARTRE, 1994, p. 95).

${ }^{30}$ Essa passividade, como bem notamos, é pensada em relação ao corpo perturbado.
} 
anos de 1938, o mágico recobre uma atividade anti-fenomenológica (psíquico) que, no decorrer das outras obras, acaba por redefinir-se como a própria potência nadificadora da consciência; e cuja tônica está enraizada na liberdade.

De uma obra à outra, o mágico advém como possibilidade permanente que a consciência possui, livremente, de negar a si mesma ou o mundo perceptivo que a cerca. Em ambos os casos (ego \& emoção), a consciência, tal como Sartre a compreende, é absolutamente livre para operar até mesmo em termos de irracionalidade e de contradição; mas esse fato não deve nos espantar e nem servir de argumento para desclassificar o rigor com o qual o pensamento filosófico sartreano é erigido pois, afinal, como o próprio Sartre reiteradamente insistiu: "o homem é sempre um feiticeiro para o homem".

\section{Referências:}

BERNET, Rudolf. "La 'conscience' selon Sartre comme pulsion et désir", in: ALTER - Sartre phénoménologue. Paris: Éditions ALTER, 2002, pp. 2342.

BRUZAN, Adinel. "Logique et théorie phénoménologique des émotions", in: Organon, 36, 2007, pp. 199-210.

CABESTAN, Philippe. L'être et la conscience: Recherches sur la psychologie et l'ontophénoménologie sartriennes. Paris: Éditions OUSIA, 2004.

CARRASCO, Alexandre de Oliveira Torres. A liberdade. Coleção Filosofias: O prazer do pensar, São Paulo: Ed. Martins Fontes, 2011. "Breve apresentação de A transcendência do Ego - Esboço de uma descrição fenomenológica, de Jean-Paul Sartre, in: Cadernos Espinosanos, $\mathrm{n}^{\circ}$ XXII, 2010, p. 173-182.

CONTAT, M. \& RYBALKA, M. Les écrits de Sartre. Paris: Gallimard, 1970.

CUMMING, Robert D. “Role-playing: Sartre's transformation of Husserl's phenomenology", in: The Cambridge Companion to Sartre. Edited by Christina Howells. New York: Cambridge University Press, 1999, pp. 3966.

DE BEAUVOIR, Simone. La force de l'âge. Paris: Gallimard, "Folio", 1980.

DE COOREBYTER, Vincent. Sartre face à la phénoménologie: Autour de "L'intentionnalité" et "La transcendance de L'ego". Bruxelles: Éditions OUSIA, 2000.

FRETZ, Leo. "Individuality in Sartre's philosophy", in: The Cambridge Companion to Sartre. Edited by Christina Howells. New York: Cambridge University Press, 1999, pp. 67-102. 
FREUD, Sigmund. "As resistências à psicanálise", in: Obras Completas. São Paulo: Ed. Companhia das Letras, 2008.

GÉLY, Raphael. "Émotion, imagination, incarnation: Réflexion à partir de l'Esquisse d'une théorie des emotions", in: Bulletin d'analyse phénoménologique VIII 1, 2012, p. 303-429.

- Ideias para uma fenomenologia pura e para uma filosofia fenomenológica. Introdução geral à fenomenologia pura. Tradução de Marcio Suzuki, prefácio de Carlos Alberto Ribeiro de Moura, São Paulo: Ed. Idéias e Letras, 2006.

. Leçons pour une phénoménologie de la conscience intime du temps. Traduit de l'allemand par Henri Dussort, Paris: PUF, 2013.

JANICAUD, Dominique. Heidegger en France. Paris: Hachette Littérature, 2001.

JEASON, Francis. Le problème moral et la pensée de Sartre. Paris: Éditions du Seuil, 1965.

LEOPOLDO E SILVA, Franklin. Ética e literature em Sartre: Ensaios introdutórios. São Paulo: Editora Unesp, 2003.

MASSELOT Nathanael; DASSONNEVILLE, Gautier. "Magie et constituition chez le premier Sartre. Vers une figure de la néantisation", in: L'Année Mosaique: objets qui nous hantent, objets qui nous tantent. Numéro dirigé par Loic Nicolas et Aline Wiame. Lille, Belgique: EME Éditions, 2012, pp. 201-218.

MOURA, Carlos Alberto Ribeiro. Crítica da razão na fenomenologia. São Paulo: ed. Nova Estella, 1989.

MOUTINHO, L.D. Psicologia e fenomenologia em Sartre. São Paulo, USP: tese de dissertação de mestrado, 1993.

33, 2003, p. $105-152$.

"Negação e finitude na fenomenologia de Sartre", in: Discurso, Sartre: psicologia e fenomenologia. São Paulo: ed. Brasilience,

1995.

MOUILLE, Jean-Marc. Sartre: Conscience, ego et psyche. Paris: PUF, 2000.

SARTRE, Jean-Paul. La transcendance de l'ego et autres textes phénoménologiques. Texte introduits et annotés par V. de Coorebyter, Paris: J. Vrin, 2003.

La transcendance de l'ego, esquisse d'une description phénoménologique. Introduction, notes et apêndices par Sylvie Le Bom, Paris: J. Vrin, 1998.

A Transcendência do Ego, esboço de uma descrição fenomenológica. Tradução de Alexandre de O. Torres Carrasco, São Paulo: FFLCH, 2010.

- A Transcendência do Ego, esboço de uma descrição fenomenológica. Tradução e prefácio de Pedro M. S. Alves. Lisboa: Edições Colibri, 1994. 
. Esquisse d'une théorie des émotions. Paris: HERMANN, 1995.

. Esquisse d'une théorie des émotions. Préface d'Arnaud Tomès. Paris: HERMANN, 2010.

- "Une idée fondamentale de la phénoménologie de Husserl: l'intentionnalité", in: Sartre, La transcendance de l'Ego et autres textes phénoménologiques. Texte introduits et annotés par V. de Coorebyter, Paris: J. Vrin, 2003.

WORMS, Frédéric. La philosophie en France au XXième siècle. Moments. Paris: Gallimard, 2009. 